\title{
Corpos (im)perfeitos e versões do inferno em chuck palahniuk e john hughes
}

\section{(im)perfect bodies and versions of hell in chuck palahniuk and john hughes}

DOI: $10.46814 / \operatorname{lajdv3n3-040}$

Recebimento dos originais: 01/05/2021

Aceitação para publicação: 30/06/2021

\author{
André Pereira Feitosa \\ Doutorado em Literatura Comparada pela UFMG \\ Instituição de atuação atual: Unifei- Campus Itabira (Universidade Federal de Itajubá- Campus \\ Itabira) \\ Endereço completo: Unifei - Campus Itabira; Rua Irmã Ivone Drumond, 200 Distrito Industrial II \\ Sala 2428 Itabira-MG CEP 35903-087 \\ E-mail: andrefeitosa@unifei.edu.br
}

\begin{abstract}
RESUMO
O romance Condenada: a vida é curta: a morte é eterna (2013), de Chuck Palahniuk, mantém referências explícitas a diversas produções cinematográficas, em especial com o filme $O$ clube dos cinco (1985), de John Hughes. A protagonista de Palahniuk, Madison Spencer, uma adolescente rica, gorda e mimada, encontra-se no inferno, presa em uma cela imunda. Percebendo que está cercada de outras quatro pessoas também condenadas, cada uma com aptidões e características físicas bem distintas (uma líder de torcida, um jogador de futebol americano, um nerd e um punk), Madison decide que o grupo deve explorar o inferno em busca de uma saída; ao invés de aceitar passivamente a danação eterna. Já a narrativa de Hughes apresenta uma metáfora do inferno. Cinco alunos provenientes de realidades diversas estão de castigo e têm como punição passar o sábado presos na biblioteca escrevendo, cada um, o inventário de suas vidas e, de forma semelhante ao grupo de Madison, também buscam uma escapatória desta funesta realidade. Este estudo comparativo entre essas narrativas está apoiado nas teorias do grotesco de Geoffrey Harpham e Margaret Miles que defendem os seguintes recursos pictóricos: caricatura, inversão e hibridização. Sob essa óptica, pode-se inferir que a narrativa de Palahniuk se espelha na versão fílmica de Hughes. Enquanto um enfoca uma representação do inferno, na qual a figura do demônio chefe é desempenhada pelo diretor da escola, o outro apresenta o inferno per se, chefiado por um Satã que, como o diretor da escola, quase nunca está presente.
\end{abstract}

Palavras-chave: Grotesco. John Hughes. Chuck Palahniuk.

\begin{abstract}
Chuck Palahniuk's Damned (2011) has explicit references to many classic movies, such as John Hughes's The Breakfast Club (1985). Palahniuk's protagonist is Madison Spencer, a rich, fat and spoiled teenager who finds herself in Hell, locked up in a dirty cell. Noticing that she is surrounded by other four condemned persons, each one with peculiar skills and physical traits (a cheerleader, a football player, a nerd and a punk), Madison decides that the group should explore Hell in search of a way out; instead of helplessly accept the eternal damnation. On the other hand, Hughes's narrative presents the metaphor of Hell. Five students from different realities are held in detention at the library of Shermer High School, in which each one has to write their lives' inventory. Just like Madison's group, they also fight to find a way out of their punishment. This comparative study is grounded on Geofrey Harpham's and Margaret Miles's theory on the grotesque, in which the pictorial resources are: caricature, inversion and hybridization. In this light, one may infer that Palahniuk's narrative mirrors itself on Hughes movie. One focuses on a representation of Hell, in which the main demon lies in the
\end{abstract}


figure of the principal. The other presents to the reader Hell per se, ruled by a Lucifer that very seldom shows up.

Keywords: Grotesque. John Hughes. Chuck Palahniuk.

\section{INTRODUÇÃO}

"[...] It's my feeling we'll win in the end [...]"

Simple Minds -Don't You (Forget About Me)

(Dedico este artigo ao VDJ Roy, da equipe Supra Sumo, e a minha amiga oitentista Natália

Alves.

John Hughes foi um renomado produtor, diretor e roteirista estadunidense. Seus filmes mais emblemáticos foram: Mulher nota 1000 (Weird Science), de 1985, O Clube dos cinco (The Breakfast Club), de 1985, A Garota de rosa-shocking (Pretty in Pink), de 1986, Gatinhas e Gatões (Sixteen Candles), de 1986, Curtindo a vida adoidado (Ferris Bueller's Day Off), de 1986, Alguém muito especial (Some Kind of Wonderful), de 1987, e Quem vê cara não vê coração (Uncle Buck), de 1989. Hughes alavancou a carreira cinematográfica de muitos jovens atores na década de 80 como Molly Ringwald, Michael Schoeffling, Anthony Michael Hall, James Spader, Emilio Estevez, Judd Nelson, Ally Sheedy, Matthew Broderick, Macaulay Culkin, Eric Stoltz, Mary Stuart Masterson, Lea Thompson, Craig Sheffer e Elias Koteas. Sucesso entre o público jovem, as tramas de seus filmes quase sempre envolvem dramas familiares e a sofrida luta de autoafirmação que a maioria dos adolescentes atravessa perante os diferentes grupos sociais. Temperadas com trilhas sonoras de renomadas bandas oitentistas como General Public, Psychedelic Furs, Orchestral Manoeuvres in the Dark, Oingo Boingo, The March Violets, The Jesus and Mary Chain, Simple Minds, e Wang Chung, os filmes de Hughes ainda são forte referência na indústria cinematográfica e em muitas produções artísticas da atualidade.

Uma forte prova da influência Hugheana em outros áreas da arte e da literatura é a trilogia Condenada, ainda inacabada, de Chuck Palahniuk. Entre os seus livros publicados no Brasil estão Clube da Luta, de 1996, que teve sua narrativa adaptada para o cinema em 1999, Sobrevivente, de 1999, Monstros invisíveis, de 1999, No Sufoco, de 2001, Assombro, de 2005, Snuff, de 2008, Condenada, de 2011 e Maldita, de 2013. Palahniuk aborda muitos temas que são tabus nas sociedades ocidentais como o suicídio, a banalização das cirurgias plásticas, cirurgias de mudança de sexo, questionamento de dogmas religiosos, ridicularização dos comunistas e esquerdistas cujos discursos não condizem com suas ações, relacionamentos familiares e interpessoais destrutivos, explicitando violências físicas e psicológicas. Seus personagens não são inocentes ou convencionais e as temáticas Palahniukeanas levam seus leitores a lugares oníricos como o interior da mente de um esquizofrênico 
e até mesmo a uma visão estereotipada e deturpada do inferno, colocando em xeque a óptica judaicocristã. Vestidas de uma crítica ácida aos valores cristalizados de poder e aos comportamentos considerados normais nas sociedades ocidentais, as obras de Palahniuk criticam muitos valores de moralidade e comportamento prescritos para homens e mulheres, invertendo seus papéis virtuosos para atitudes monstruosas.

\section{UMA VERSÃO GROTESCA DE $O$ CLUBE DOS CINCO}

A palavra "grotesco" carrega em si algo que deve estar escondido e, historicamente, suas formas destoam dos padrões de beleza e estética para uma determinada cultura em um determinado tempo. Para os autores Muniz Sodré e Raquel Paiva, o grotesco está relacionado ao rebaixamento de algo quando comparado a modelos sublimes. Ele mostra "uma combinação insólita e exasperada de elementos heterogêneos, com referência frequente a deslocamentos escandalosos de sentido, situações absurdas, animalidade, partes baixas do corpo, fezes e dejetos [...]”. Essa justaposição de elementos irá causar o que os autores chamam de "desarmonia do gosto ou disgusto" (SODRÉ; PAIVA, 2002, p. 17, grifos dos autores). A obra Condenada, de Chuck Palahniuk, explicita em sua narrativa diversas características desse desgosto, dessa ruptura com o belo, mencionado por Sodré e Paiva, quando as criaturas e as paisagens infernais são descritas.

Outro teórico do grotesco é Geoffrey Galt Harpham que, reforçando os argumentos de Sodré e Paiva, afirma que o grotesco é de fluida definição, e "depende da cultura fornecer as convenções e suposições que determinam suas formas particulares" (HARPHAM, 2006, p. XXVI, tradução nossa), ${ }^{1}$ ou seja, o que faz com que uma determinada pessoa seja vista como diferente não é a etnia ou as diferenças corporais essenciais mas, sim, a potencialidade para quebrar paradigmas e, assim, ser percebida como um elemento ameaçador da norma. Os seres monstruosos seriam "aquelas espécies que são impuras [...], aqueles que são membros imperfeitos de sua classe, ou cuja própria classe atrapalha o esquema geral do mundo" (HARPHAM, 2006, p. 83, tradução nossa). ${ }^{2}$ Ou seja, o ser que desorganiza os valores de determinada cultura ou que ameaça a ordem considerada natural de comportamento social, pode, em algumas situações, ser visto como algo monstruoso.

Também unida à tentativa de elucidar o grotesco nas artes e na literatura, a crítica feminista Margaret Miles defende que ele é praticamente impossível de ser definido. No entanto, ele é facilmente categorizável em três recursos retóricos e pictóricos: "caricatura, inversão e hibridização" (MILES,

\footnotetext{
1 " [...] it is up to the culture to provide the conventions and assumptions that determine its particular forms".

2 " $[\ldots]$ those species which are unclean [...], those which are imperfect members of their class, or whose class itself confounds the general scheme of the world".
} 
2006, p. 155, tradução nossa). ${ }^{3}$ Esses recursos são amplamente utilizados por Palahniuk em sua narrativa. A característica principal da caricatura é o exagero das formas. A inversão aparece quando um personagem ou um modelo de perfeição encontra o seu contraexemplo, uma forma ou pessoa que é seu avesso; causando estranhamento. A hibridização se caracteriza pela justaposição de elementos que não se fundem ou que não se misturam na natureza, como um corpo humano mesclado a partes de animais ou plantas. Condenada apresenta uma versão invertida dos personagens de $O$ Clube dos cinco, explicitando protagonistas cujos corpos e comportamentos são o oposto do apresentado por John Hughes.

\section{O CLUBE DOS CINCO DOS VIVOS VERSUS O CLUBE DOS CINCO DOS MORTOS}

O Clube dos cinco, de John Hughes, começa e termina com a mesma frase; na qual os personagens são descritos pelos seus estereótipos: um atleta, uma lixeira, uma princesa, um cérebro e um criminoso. A diferença é que no início do filme a voz que narra é a de Brian, o cérebro, que ficou encarregado de escrever a redação para o grupo quando, na verdade, cada personagem deveria escrever a sua. No fim do filme cada personagem fala alto o estereótipo que o qualifica; sugerindo que todos adquiriram voz própria. A narrativa mostra cinco adolescentes que têm que passar um sábado inteiro de castigo na biblioteca da escola, para pagar por algum delito cometido. A atriz Molly Ringwald faz o papel de Clair Standish, a princesa; uma adolescente mimada e rica que usa roupas de grife, brincos de diamante e o pai a leva até a escola em um BMW novo. Anthony Michael Hall faz o papel de Brian Ralph Johnson, o cérebro, cuja aparência é do estereótipo de um nerd. Emilio Estevez incorpora o personagem Andrew Clark, um atleta cujo pai exige que ele seja forte e bom nos esportes; sem se preocupar muito com a formação de seu caráter. O ator Judd Nelson faz o papel de John Bender, o criminoso, um adolescente que vai armado para a escola, é traficante de drogas e vem de um lar violento no qual sofre agressões físicas e psicológicas de seus pais. Finalmente, a atriz Ally Sheedy faz o papel de Allison Reynolds, a lixeira, uma personagem que se veste mal, se alimenta mal, não toma banho, é retraída e ignorada por seus pais.

O diretor da Shermer High School, Richard Vernon, interpretado pelo ator Paul Gleason, tem o estereótipo de um educador desalmado, preocupado apenas em cumprir seu dever de forma minimalista e receber seu salário. Ele grita e humilha verbalmente os cinco alunos e deixa como punição a tarefa de cada um escrever um inventário de sua vida, uma redação que deve ter no mínimo 1000 palavras, e que deverá ser entregue ao fim do dia. A atividade poderia até ter sido frutífera se não fosse tão mal conduzida. Na verdade, o diretor apenas entrega as folhas de papel e os lápis aos cinco

\footnotetext{
3 “[...] caricature, inversion, and hybridization.".
} 
alunos e sai da biblioteca, retornando ao seu gabinete cuja mesa é desorganizada e o único elemento de decoração é um calendário com uma mulher de biquíni; sem lhes prestar nenhum tipo de monitoramento ou auxílio pedagógico.

Ao final do filme, depois que Claire, Brian, Andrew, John e Allison adquirem um certo nível de confiança entre si, os cinco passam por uma espécie de terapia em grupo não monitorada, na qual cada um compartilha seus sofrimentos e as cobranças por pertencerem a grupos sociais tão diferentes, aprendendo, de certa forma, a reavaliar as normas de comportamento impostas por suas famílias e a questionar valores sociais artificialmente construídos para segregar as pessoas.

Palahniuk, utilizando as categorizações grotescas defendidas por Margaret Miles, inverte a obra prima Hugheana em personagens que se assemelham fisicamente aos personagens do filme mas, surpreendentemente, são diferentes emocionalmente. A narrativa se dá em primeira pessoa na voz de Madison Desert Flower Rosa Parks Coyote Trickster Spencer, cujo nome caricato ela mesma admite ser "um segredo pessoal monstruoso" (PALAHNIUK, 2013, p. 207). Seus pais quando jovens foram hippies mas, no momento da narrativa, são bilionários atores de Hollywood que discursam nas mídias como pessoas preocupadas com a natureza e com a extrema pobreza dos países subdesenvolvidos, como defensores das ideologias de esquerda e como caridosos; chegando a adotar crianças famintas dos países de terceiro mundo. Na verdade, eles apenas se preocupam com suas próprias imagens de filantropos e estão sempre em busca do próximo milhão de dólares a ser conquistado e de como seus fãs os veem nos tabloides e na TV; em especial na entrega do óscar. Eles têm apenas Madison como filha biológica.

Buscando uma intertextualidade com o filme de Hughes, a obra de Palahniuk inicia com Madison acordando no inferno e escrevendo uma espécie de diário/inventário para Satã que, de certa forma, se assemelha ao diretor da escola Richard Vernon porque ele nunca está presente e, supostamente, irá fazê-la sofrer. Sem entender bem o que está se passando com ela, Madison escreve:

Está aí, Satã? Sou eu, Madison. Acabei de chegar aqui, no Inferno, mas não é minha culpa, exceto talvez por ter morrido de overdose de maconha. Talvez esteja no Inferno porque sou gorda-uma verdadeira leitoa. Se é possível ser mandado ao Inferno por ter baixa autoestima, é por isso que estou aqui. Quem dera pudesse mentir e dizer a você que sou um palito, loira e peituda. Mas pode acreditar em mim: sou gorda por uma razão bem boa. Para começar, deixe que eu me apresente. (PALAHNIUK, 2013, p. 5, grifos do autor).

Percebe-se neste apelo de Madison que ela se sente excluída do centro das atenções do universo hollywoodiano, no qual seus pais vivem, por seu corpo se distanciar dos padrões de perfeição feminina impostos pela sociedade estadunidense, nos quais ela deveria ser magra, caucasiana e com seios grandes. A personagem de Palahniuk é grotesca por seu corpo se alijar desse padrão de beleza imposto pela indústria cinematográfica. A pessoa gorda, principalmente se for uma mulher em sociedades 
patriarcais, pode ser vista como preguiçosa e, até mesmo, desprovida de caráter. Condenada nos mostra uma personagem que destrói esses paradigmas ocidentais. A gorda, no final das contas, irá desafiar demônios, ser líder de um grupo de pessoas condenadas e conquistar seu espaço no inferno.

No final da narrativa, Madison, depois de subornar um demônio com uma barra de nougat Big Hunk, conhece a sua verdadeira causa mortis: seu irmão adotivo, Goran, após ambos fumarem maconha e tomarem LSD, a enforca com uma "faixa de camisinhas da Hello Kitty" (PALAHNIUK, 2013, p. 291). Até então ela acreditava que havia morrido de uma overdose mas, na verdade, fora assassinada. O inferno de Palahniuk deveria ser um local de tortura e sofrimento para Madison. No entanto, é no inferno que a protagonista consegue se entender melhor cada vez que escreve um capítulo do seu inventário para Satã, que nunca o lê, e passa por uma transformação na qual ela não deseja mais ser vítima dos padrões pré-estabelecidos de perfeição feminina.

Condenada mostra de forma explícita que é uma contra-narrativa de $O$ Clube dos cinco. Madison afirma no início da obra que:

Para ser sincera, sempre que assisto ao clássico de John Hughes, Clube dos cinco, e Molly Ringwald leva a pobre Ally Sheedy ao banheiro feminino, e então sai de lá com ela naquela maquiagem horrenda dos anos 1980, aquele blush nas bochechas, o cabelo preso com um laço e lábios pintados naquele vermelho-vermelho, datado como uma versão vagabunda de boneca de porcelana esgotada de Ringwald, Sirigaita da Silva em conformidade com a revista Vogue, a pobre Ally reduzida a uma tipo tão grotesco de vida, com ar de pôster do Nagel, sempre grito para a televisão: "Corra, Ally!". Sério, grito mesmo: "Lave o rosto, Ally, e saia correndo!". (PALAHNIUK, 2013, p. 20-21, grifos do autor).

A intertextualidade com o filme de Hughes é explícita. O excerto acima mostra que a protagonista de Palahniuk conhece o filme e que ela se identifica com a personagem lixeira, porque ambas têm pais que as negligenciam. No entanto, enquanto a maioria dos expectadores que assistem a essa cena de Ally Sheedy se emocionam por interpretarem que finalmente ela ganhou uma amiga e que, depois de maquiada, poderá interagir melhor com as amigas da Claire, a princesa, Madison vê essa cena como Ally, a lixeira, desistindo de sua identidade. Madison se identifica com a personagem suja, mas, emocionalmente falando, ela é na verdade o seu inverso. Ao longo da narrativa, Madison repetidas vezes verbaliza e reafirma a sua identidade: “[p]osso ser gorducha e sem peito, míope e defunta, mas NÃO pamonha" (PALAHNIUK, 2013, p. 20, ênfase do autor). Talvez por medo de perdêla em algum momento, uma vez que o inferno rouba toda a dignidade que uma pessoa possa ter, ela não se cansa de repetir:

O que quero dizer é: construí toda minha identidade baseada em ser esperta. As outras meninas, principalmente as periguetes, escolhem ser bonitas; é uma decisão fácil quando você é jovem. Como minha mãe diria: "Todo jardim fica bonito em maio". Traduzindo: todo mundo é de alguma forma atraente quando é jovem. Entre as jovens, é uma escolha automática competir no nível de atração física. Outras meninas, aquelas 
condenadas por narigões ou pele detonada, decidem ser loucamente divertidas. Outras ficam atléticas ou anoréxicas ou hipocondríacas. Muitas meninas escolhem o amargo, solitário caminho de uma vida em ser a Irritadinha de Magalhães, armada com sua raiva de língua afiada. Outra escolha de vida é se tornar a violenta e engajada estudante política. [...] Mas, apesar de tantas opções, escolhi ser esperta - a garota gorda e inteligente que possui o cérebro brilhante, a estudante que só tira A, que usa sapatos sensatos duráveis e abstém-se do voleibol, manicures e risadinhas. (PALAHNIUK, 2013, p. 215).

Nesta análise de Madison é possível entender que a menina de 13 anos está amadurecendo e que esse período no inferno serviu para que ela questionasse os valores de perfeição feminina. No inferno, Madison decide reavaliar a sua condição passada em que era uma adolescente rica e inserida em Hollywood; ela decide sair de uma posição insegura para uma posição assertiva. O primeiro demônio que ela enfrenta e domina é a giganta "Psezpolnica", um "demônio sérvio" com a aparência de um "imenso tornado feminino nu" (PALAHNIUK, 2013, p. 90). Após ganhar a luta, escalando suas enormes pernas peludas e estimulando o seu clitóris gigante até provocar-lhe um orgasmo, Psezpolnica ajuda o grupo a desbravar o inferno; carregando os cinco adolescentes em sua mão: "Estou morta [Madison], e andando na palma fechada de uma mulher-demônio gigante enquanto ela cavalga pela paisagem infernal, que queima por quilômetros. Na minha companhia estão meus novos compatriotas: Leonard, Patterson, Archer e Babette. O cérebro, os músculos, o rebelde e a rainha do baile". (PALAHNIUK, 2013, p. 96). Aqui, pela primeira vez, Madison define de forma clara a sua versão grotesca de $O$ Clube dos cinco; na qual os personagens são opostos aos modelos apresentados por Hughes. Em Condenada, o cérebro não é bom de ciências exatas. O seu conhecimento é profundo apenas nas áreas das humanidades. $\mathrm{O}$ atleta não é bom de briga, e nem ao menos tem falas significativas. Ele é o estereótipo dos homens do século XXI que investem apenas na sua aparência, cultuando o corpo. O criminoso cede lugar a um punk, com diversos body piercings e alfinetes de fralda espetados pelo corpo. A rainha do baile, Babette, é bonita mas todas as suas roupas e acessórios são cópias dos originais vendidos nas lojas de grife, distanciando-se da princesa Hugheana que veste-se luxuosamente. Aqui, sob a óptica de Margaret Miles, tem-se o grotesco por inversão, ou versões deturpadas e caricatas do modelo original apresentado em $O$ Clube dos cinco.

O grupo grotesco liderado por Madison, a menina gorda, se mantém unido até o fím da narrativa. Alguns mortos condenados ao inferno têm a regalia de ir ao planeta Terra na noite de Halloween. Eles podem ir de porta em porta arrecadar chocolates e doces, a única moeda de troca aceita pelos demônios no inferno. No entanto, têm que voltar exatamente à meia noite. Do contrário, terão que ficar vagando pela Terra sozinhos, como almas penadas, até o ano seguinte com a chegada do próximo Halloween. Na hora da partida para a Terra, Madison diz: "No fim fomos só nós, Archer, Emily, Leonard, Babette, Patterson e eu, batendo de porta em porta. O Clube dos Cinco dos Mortos" 
(PALAHNIUK, 2013, p. 290). Aqui, Palahniuk deforma a obra de Hughes novamente, apresentando ao leitor um Clube dos cinco grotesco que contém seis integrantes; após a chegada de mais uma adolescente ao inferno: Emily. E esse grupo não é composto por adolescentes vivos, ao contrário, é o clube dos cinco dos mortos.

\section{EXPLORANDO AS PAISAGENS DO INFERNO}

Madison, a princípio, não sabe que foi trazida ao inferno de limusine. Ela acorda jogada no chão de uma cela imunda, cujas barras de ferro têm uma gosma e o chão está repleto de balas, pipocas e diversos farelos de doces dos quais ela não pode comer. Em outra cela Babette lhe pergunta as horas e diz para Madison não comer os doces porque estão sujos. Segundo a líder de torcida, todas as pipocas e balas que caem das mãos dos espectadores em teatros e cinemas vão parar no inferno. Não somente as balas e pastilhas mas tudo que é descartado no planeta Terra vai parar no inferno.

A medição do tempo é outra característica presente em ambas as obras. O filme de Hughes constantemente mostra um relógio de parede que está adiantado, mas os alunos não sabem, e cujos ponteiros, na percepção dos adolescentes, anda devagar demais. No inferno de Palahniuk o tempo é algo impreciso e apenas Madison, que tem um relógio de boa qualidade que pode indicar o dia e a hora precisos, pode confortar Babette. Ao longo da narrativa o leitor descobre que Babette cometeu suicídio e não veio de limusine; ela foi jogada para dentro do inferno. Durante sua queda, as roupas de grife falsificadas se despedaçaram e o seu relógio Swatch derreteu. Interessante notar que Madison, no início da narrativa, já deixa escapar que ira recrutar pessoas para vir ao inferno e dá uma dica ao leitor:

\footnotetext{
Para todos vocês que vivem, que andam por aí, tomam multivitaminas e se ocupam sendo luteranos ou fazendo colonoscopia, é preciso investir num relógio de pulso de boa qualidade, durável, com funções de dia e data. Não conte com recepção de sinal de celular no inferno, e nem por um segundo que vai ter a prudência de morrer com o carregador nas mãos, ou mesmo que vai se encontrar preso numa cela enferrujada com uma solução compatível para a falta de eletricidade. Não significa que tenha de comprar um Swatch. Swatches são feitos de um material parecido com plástico, e plástico derrete no Inferno. Faça um favor a si mesmo e invista num relógio com pulseira de couro de qualidade ou do tipo feito com metal ajustável e flexível. (PALAHNIUK, 2013, p. 32).
}

O filme $O$ Clube dos cinco mostra adolescentes que incessantemente confirmam o tempo no relógio de parede da biblioteca para contar os minutos que faltam para o seu suplício terminar, exatamente às cinco da tarde. Em Condenada, como o próprio título sugere, não há esperança. Segundo Madison, sua "maior fraqueza ainda é a esperança. No Inferno, a esperança é um hábito bem, bem feio, como fumar ou roer as unhas. Esperança é algo que exige muita tenacidade para se deixar de lado. É um vício a vencer." (PALAHNIUK, 2013, p. 28). Contar o tempo e saber exatamente em que dia se está alimenta uma falsa esperança de que um dia o castigo chegará a um fim. Um dos aspectos que 
diferem Madison de Babette é que a primeira pede para o punk utilizar um dos seus alfinetes de fralda para abrir os cadeados das celas e se recusa a ficar presa em uma prisão imunda. Já Babette encara tudo com um tom fatalista, não sabe encarar seus problemas de forma madura e sensata. Ao longo da narrativa chega ao conhecimento de todos que ela foi jogada no Inferno por ter cortado os próprios pulsos (PALAHNIUK, 2013, p.275) e o suicídio é uma espécie de infração grave. Dar cabo da própria vida também reflete que, no caso de Babette, foi uma hiper-reação a algum problema possivelmente fútil na sua vida terrena.

Ao desbravar o inferno, Madison descobre várias paisagens sui-generis que aumentam a característica de locus horrendo que tal lugar possui. Para um local de danação eterna no qual os infratores devem sofrer, o inferno de Palahniuk é bastante organizado e sua topografia bastante peculiar. A protagonista diz que "[a] vida no Inferno é como desenho animado antigo da Warner Bros., no qual as personagens são eternamente decapitadas por guilhotinas e desmembradas por explosões de dinamite, depois restauradas por completo para o próximo assalto. É um sistema que não deixa de trazer conforto e monotonia". (PALAHNIUK, 2013, p. 37). Os protagonistas de Condenada, por terem saído das celas, irão encontrar diversos tipos de demônios que irão desmembrá-los e, como é esperado nos desenhos animados pastelões da década de 80 , seus corpos se reintegram para serem destruídos novamente em outro episódio. Aqui, Palahniuk se utiliza de mais uma intertextualidade fílmica.

As paisagens do inferno nas quais tais suplícios acontecem podem ser: o escamoso e gordurento Deserto de Caspa (PALAHNIUK, 2013, p. 55); as Grandes Planícies de Caco de Vidro (PALAHNIUK, 2013, p. 55), o Grande Oceano de Esperma Desperdiçado que, segundo Archer: “Todas as ejaculações expelidas em masturbações durante toda a história da humanidade [...] escorre e se acumula alí" (PALAHNIUK, 2013, p. 56); o Pântano dos Abortos dos Semiformados (PALAHNIUK, 2013, p. 57); o Lago de Saliva Quente (PALAHNIUK, 2013, p. 91); o vasto Vale das Fraldas Descartáveis Usadas (PALAHNIUK, 2013, p. 224) e termina em um enorme simulacro de repartição pública, ou uma espécie de delegacia de polícia do inferno, na qual os condenados podem rever os seus processos contendo o histórico de seus atos que os condenaram ao inferno.

Acabei descobrindo que meus registros de condenação se perderam. Ou ainda vão chegar. Ou meus registros foram acidentalmente destruídos. Qualquer que seja o caso, sou forçada a começar do zero, convocada para fazer um teste básico no detector de mentiras e um teste para o uso de drogas. Ao que parece, Babette não é tão inútil quanto imaginava a princípio. Ela ultrapassou um bom bocado de papelada e redundâncias burocráticas, levando nosso pequeno time por um labirinto de corredores e escritórios, subornando burocratas de baixo nível com barras de Hershey e SweeTarts. O Inferno está a séculos de estabelecer uma cultura de economia de papel, e a maior parte do chão está forrada de papéis até os joelhos de registros extraviados, pastas vazias, leituras descartadas de polígrafos, Butter Rum Life Savers e baratas. A caminho do teste, Archer me aconselha a não cruzar os braços, não olhar para a direita nem para cima - gestos físicos que entregam um mentiroso. Depois que entregamos o formulário preenchido e 
passamos ao demônio atendente um Kit Kat, Babette me deseja boa sorte. Ela me dá um abracinho, sem dúvida deixando marcas sujas de mão atrás do suéter. Babette, Leonard, Patterson e Archer esperam num corredor externo enquanto passo por uma porta para o quarto todo branco de testes. O polígrafo. O demônio inflando a braçadeira de pressão sanguínea no meu braço. Você pode se lembrar desse demônio da obra prima clássica de Hollywood, $\mathrm{O}$ exorcista, no qual ele possui uma garotinha, filha mimada e precoce de uma estrela de cinema de meia-idade. Fale sobre Déjà vu. [...]. (PALAHNIUK, 2013, p.107-108, grifos do autor).

Analisando o excerto acima percebe-se que $O$ Clube dos cinco não é a única referencia fílmica que Palahniuk utiliza na confecção do inferno de Condenada, o filme $O$ Exorcista também marca presença no romance. Interessante perceber que tanto a narrativa de Hughes quanto a narrativa de Palahniuk criticam a corrupção. Quando o diretor da escola, em $O$ Clube dos cinco, decide ler os arquivos confidenciais de seus colegas de trabalho e é pego no ato pelo faxineiro da escola, paga cinquenta dólares de suborno para que o funcionário não o denuncie. Em Condenada, Palahniuk ironiza todo o processo de pagamento de propinas para receber favores dos funcionários-demônios, estabelecendo que a moeda de troca entre condenados e funcionários inescrupulosos são os chocolates encontrados na terra como M \& M's, Milkyway, Snickers, Kit Kat, e outras guloseimas que os mortos podem coletar quando ganham o direito de passar as noites de Halloween na Terra. Finalmente, Palahniuk acidamente critica as repartições públicas, comparando o sistema burocrático que a população normalmente enfrenta ao sistema burocrático do inferno, no qual, segundo a protagonista, é um lugar no qual não se pode ter esperança.

\section{SHERMER HIGH SCHOOL VERSUS O INFERNO}

A menina gorda de Condenada evolui ao longo da obra saindo de sua zona de conforto para uma posição de confronto. Aqui percebe-se mais uma inversão, aos moldes de Margaret Miles, para se caracterizar o grotesco. Em O Clube dos cinco os adolescentes também decidem de sair de sua cela metafórica, a biblioteca, para explorar a escola; uma vã tentativa de escapar de seus castigos porque em cada corredor que eles atravessam acabam encurralados por grades e portas trancada. Em a Condenada os adolescente estão presos e, se recusando ser uma vítima, Madison lidera uma fuga na qual os cinco jovens fogem e desbravam o inferno. $\mathrm{O}$ que ambas as narrativas não conseguem solucionar é o tom maniqueísta, e um tanto fatalista, que os personagens sofrem; especialmente em $O$ Clube dos cinco. A solução encontrada por Hughes foi deixar que cada adolescente compartilhasse um pouco do que eles têm entre si. A princesa dá de presente um de seus brincos de diamante para o criminoso e melhora a aparência da lixeira com maquiagem. O cérebro escreve uma redação única na qual todos assinam. $\mathrm{O}$ atleta repensa seus conceitos de amizade e inclui o cérebro e a lixeira em seu círculo e, no fim do filme, o criminoso comemora os novos amigos que fez enquanto volta a pé para 
casa. A obra Palahniuk traz uma possibilidade de salvação apenas para Madison, a menina gorda e mimada, que termina a narrativa afirmando: "E, sim, tenho treze anos, estou morta e sou uma menina. Posso ser um tanto sádica e um tanto infantil... mas pelo menos não sou uma vítima, não mais. Tenho esperança. Tenho esperança, logo existo”. (PALAHNIUK, 2013, p. 302). Ter esperança, no inferno, é um artigo de luxo que foi concedido apenas à Madison. A seus colegas do Clube dos cinco dos mortos resta apenas resignar-se em serem comandados por seu novo líder e aceitar que pouco poderá ser feito por eles, pelo menos neste primeiro volume da trilogia. No entanto, no filme de Hughes, a música tema do filme, Don’t You (Forget About Me), da banda Simple Minds, sugere que um integrante não irá se esquecer do outro, que o grupo permanecerá unido e que todos são vencedores. 


\section{REFERÊNCIAS}

HARPHAM, Geoffrey Galt. On the Grotesque: Strategies of Contradiction in Art and Literature. Aurora: Davies Group Publishers, 2006. 273 p.

MILES, Margaret R. Carnal Knowing: Female Nakedness and Religious Meaning in the Christian West. Eugene: Wipf \& Stock Publishers, 2006. 254 p.

O CLUBE dos cinco. Direção de John Hughes. Manaus: Universal Studios, 2005. 1 videodisco. (97 min.). Tradução de: The Breakfast Club.

PALAHNIUK, Chuck. Condenada: A vida é curta: A morte é eterna. Tradução de Santiago Nazarian. São Paulo: LeYa, 2013. 302 p.

SIMPLE MINDS. Don't You (Forget About Me). Intérprete: Jim Kerr. In: The Breakfast Club Soundtrack. New York: A \& M Records, c1985.1 CD, faixa 1 (4 min 21s).

SODRÉ, Muniz; PAIVA, Raquel. O império do grotesco. Rio de Janeiro: MAUAD, 2002. 156 p. 